\title{
Cellular immunity in Apis mellifera : studying hemocytes brings light about bees skills to confront threats
}

\author{
Pedro Negri ${ }^{1,2}$, Matias MAGGI ${ }^{1}$, Leonor RAMIREZ ${ }^{2}$, Nicolas SzAWARSKI ${ }^{1}$, \\ Leonardo De Feudis ${ }^{1}$, Lorenzo Lamattina ${ }^{2}$, Martin Eguaras ${ }^{1}$ \\ ${ }^{1}$ Centro de Investigación de Abejas Sociales (CIAS), Facultad de Ciencias Exactas y Naturales, Universidad Nacional de \\ Mar del Plata (UNMdP, CP 7600), CONICET, Mar del Plata, Argentina \\ ${ }^{2}$ Instituto de Investigaciones Biológicas, CONICET-Universidad Nacional de Mar del Plata (UNMdP, CP 7600), Mar del \\ Plata, Argentina
}

Received 28 April 2015 - Revised 30 October 2015 - Accepted 24 November 2015

\begin{abstract}
Honey bee colonies are threatened by different stress factors around the world. Considerable efforts are being devoted to understanding honey bee defences to confront different kinds of stress factors. Despite the importance of honey bee hemocytes in resisting disease, detailed information about their role in response to challenge is still scarce. This manuscript combines the results obtained in studies which focused on the cellular defences of Apis mellifera, aiming to show how the understanding of the cellular components of the immune system is central to developing new strategies to enhance bees' fitness.
\end{abstract}

\section{Apis mellifera / honey bee / hemocytes / immune system}

\section{INTRODUCTION}

The recent decline in managed honey bee populations has attained scientific, ecological and economic concern. It has been attributed to the combination of several honey bee stresses such as parasites, pathogens (including virus, bacteria, etc.), pesticides and nutritional deficiencies due to habitat fragmentation among others (Martin et al. 2012; Neumann et al. 2012; Wagoner et al. 2013; Alaux et al. 2014; Steinmann et al. 2015). It has been also proposed that the diseases caused by infectious agents generate a major selective pressure on honey bees. By this mean, chronic increases in individual mortality and morbidity may lead directly to hive collapse or cause long-

Corresponding author: P. Negri, pedronegri1@yahoo.com.ar; M. Eguaras,mjeguaras@gmail.com Manuscript editor: Yves Le Conte term reductions in hive-level fitness due to productivity loss (Jefferson et al. 2013).

Lately, the increased mortality and colony loss of honey bees have been linked to an impaired immune competence (Gätschenberger et al. 2013; Alaux et al. 2014; Steinmann et al. 2015). Thus, the study of Apis mellifera immune system has become a key research topic in the last years in view of the fact that it could provide basic information to better understand how honey bees defend themselves against parasites and pathogens.

Insects have a well-developed innate immune system comprised of humoral and cellular responses (Strand 2008). Humoral defences refer to soluble effector molecules such as antimicrobial peptides, complement-like proteins and enzymatic cascades that regulate melanin formation and clotting. Cellular immunity is comprised by cellmediated responses like phagocytosis, nodulation, encapsulation and wound closure (Strand 2008; Marmaras and Lampropoulou 2009). Particularly, social insects can defend themselves through their innate immune system, but they have also 
developed group-level strategies to prevent disease transmission (Alaux et al. 2012; Wilson-Rich et al. 2009). This so-called social immunity relies mainly on behavioural responses to infection. WilsonRich et al. introduced the term 'antiseptic behaviour' that includes activities performed by bees such as grooming, hygienic behaviour, undertaking, avoidance, glandular secretions and use of resins in the nest. Differences between individuals and species in these immune parameters can reflect differences in infection risk, life expectancy and biological function (Schmid et al. 2008).

Hemocytes (blood cells) and the (prophenol-) phenoloxidase (proPO) system constitute the immediate response of the innate immune system in insects (Schmid et al. 2008; Schmid-Hempel 2005; Eleftherianos and Revenis 2011). Indeed, hemocytes are the primary mediators of cell-mediated immunity (Marmaras and Lampropoulou 2009) because the elimination of organisms entering the insect hemocoel requires that hemocytes be able to recognize and respond to the invading species (Clark et al. 1997). When recognizing a surface as foreign, hemocytes quickly transform from resting nonadherent cells into activated adherent cells that first adhere as a monolayer or as foci to the foreign surface (Nardi et al. 2006). After non-self recognition, the response of the insect hemocytes is to 'spread' (Gillespie and Kanost 1997). If the foreign agent is small, this spreading ability promotes particle phagocytosis, while larger foreign objects (or many small foreign objects together) would be subject to nodulation or encapsulation owing to the cooperative action of a number of hemocytes (Eleftherianos et al. 2009). Nodulation is an insect cellular defence reaction responsible for clearing large numbers of bacterial cells from circulation in response to infection (Horohov and Dunn 1983). In most insects, multicellular parasites and other foreign targets entering the hemocoel are eliminated by cellular encapsulation (Strand 2008). In this sense, inhibiting hemocyte spreading is a common strategy employed by many entomopathogens (Dean et al. 2004). This implies that such changes in hemocyte behaviour are major components of insect defence (Eleftherianos et al. 2009).

Given the worldwide concern of maintaining healthy populations of pollinators, the study of cellular immunity in honey bees has surprisingly received little attention (Marringa et al. 2014). even though several relevant studies have addressed humoral and molecular approaches (Evans et al. 2006) and social immunity (Wilson-Rich et al. 2009). The study of $A$. mellifera cellular immunity has been discontinued for many years. A few works concerning honey bee hemocytes characterization and the effects of Varroa destructor parasitism on A. mellifera blood cells are currently available (Price and Ratcliffe 1974; Fluri et al. 1977; Van Steenkiste et al. 1988; Wienand and Madel 1988; Beisser et al. 1990; de Graaf et al. 2002; Sapcaliu et al. 2009). Therefore, strategies to monitor the hemocytes subsets which could contribute to a better understanding of the effect of pathogens in colony failure are in urgent need (Marringa et al. 2014).

Hemocyte analysis in honey bees should become the focus of priority in research and allow answers to questions posed by honey bee decline. This manuscript centres on new approaches regarding cellular immunity of $A$. mellifera and provides a summary of the literature pertaining to the hemocytes of the western honey bee. The aim is to contribute with a useful collection of results and perspectives about resistance to diseases deduced through the analysis of the bees' host defence cells. Given the fact that the activation of the melanisation system results from the cooperative action of humoral and cellular defences during wound healing, encapsulation and nodulation (Markus et al. 2005; Marmaras and Lampropoulou 2009; Eleftherianos and Revenis 2011). the melanogenesis response is taken into account in this review. The key role reported for natural occurring compounds in $A$. mellifera cellular responses is also described with possible application in the field to help bees confront different stress factors such as diseases, pesticides and winter through an improved nutritional quality. By doing so, we aim to highlight the relevance of studding $A$. mellifera immunity at a cellular level.

\section{WHAT IS IT KNOWN ABOUT $A$. MELLIFERA'S HEMOCY TIC RESPONSE?}

Holometabolous insects undergo drastic morphological and physiological changes throughout 
their development. In these insects, the cellular elements in the larval hemolymph may differ significantly from those present in the adult (Schmid et al. 2008; Wilson-Rich et al. 2008; Manfredini et al. 2008; Negri et al. 2013, 2014a, b and 2015).

A. mellifera represents an ideal organism for the study of the changes in the immune system associated to ontogeny because it combines a holometabolous development within a eusocial caste system (Schmid et al. 2008; Wilson-Rich et al. 2008; Laughton et al. 2011). This has been supported by a large number of studies on $A$. mellifera (Schmid et al. 2008; Wilson-Rich et al. 2008; Laughton et al. 2011; Negri et al. 2013, 2014a, b, 2015).

Regarding particularly the cellular defence, Wilson-Rich et al. (2008) measured the number of hemocytes in hemolymph and the encapsulation response, across four developmental stages: larvae, pupae, nurses and foragers. The authors found that honey bee brood has more hemocytes than adults do, being larvae and pupae the two stages with the highest total hemocyte counts. However, no difference in encapsulation response was accounted for between developmental stages. In another study, Schmid et al. (2008) worked with immunologically naive workers, queens and drones and stated that, in all three adult phenotypes, hemocyte number continuously decreased with age, evidencing that reduction of hemocyte in foragers is not worker-specific but represents a general phenomenon occurring in all honey bee adult phenotypes.

In 2001, Bedick et al. reported that nodulation reactions might not occur in honey bee foragers upon infection. Most recently, Gätschenberger et al. (2013) examined the immune strength of honey bees across all developmental stages and found that newly emerged adult worker bees and drones were able to activate the hemocytic responses they analysed. They pointed out that the number of viable bacteria circulating in the hemolymph of challenged bees declined rapidly after the injection of the bacteria (Escherichia coli) coinciding with a rapid increase in detectable melanised nodules. They postulated that this could be attributed to a constitutively active cellular immune response comprising mainly phagocytosis and nodulation. This means that the observation accounted for by Bedick et al. (2001) cannot be fully supported because Gätschenberger et al. (2013) detected nodules in the hemocoel of forager bees as well as in 9-day old hive bees 24-h postinjection with bacteria at a reduced amount as compared to newly emerged worker bees. However, Gätschenberger et al. (2013) also showed that honey bee workers of increasing age lost their capacity to produce visible nodules, culminating in the complete absence of nodulation reactions in winter bees.

Worker and drone larvae are well prepared to cope with bacterial infections that invade the hemocoel, but the formation of nodules might be impaired (Gätschenberger et al. 2013). Presumably, bacteria could be cleared from larvae hemolymph through phagocytosis. However, considerable efforts are needed to better understand this mechanism in larvae.

Honey bee pupae contain a high concentration of hemocytes throughout their development (Gätschenberger et al. 2013). However, worker and drone pupae were completely unable to activate cellular defence reactions upon artificial bacterial challenge (Gätschenberger et al. 2013). This absence of immune reaction in pupae could not be explained by these authors.

In 2014, Negri et al. (2014a) presented new data concerning the cellular immune response of A. mellifera fifth instar larvae (L5) and newly emerged workers (W). These authors described that hemocytes from A. mellifera L5 and W displayed different appearance and yielded behavioural differences regarding attachment and spreading in vitro. Clearly, the metamorphosis between these two ontogenic stages played a key part on A. mellifera cellular immune defence. Nevertheless, hemocytes extracted from L5 and W exhibited strong similarities with respect to their general (multicellular) behavioural pattern. After comparing their results with previous reports of hemocytic behaviour in other insect species, these authors proposed that the different hemocyte types found in L5 larvae and adults were granulocytes and plasmatocytes denoting a multi-hemocytic response related to an encapsulation-like process (Negri et al. 2014a).

Recently, a new work has reported a rapid method for examining honey bee hemocyte 
profiles (Marringa et al. 2014). The authors used flow cytometry accompanied with microscopic analyses to describe the cellular components and particles present in hemolymph of adult honey bees representing a step forward from a previous work conducted by De Graaf et al. (2002). De Graaf et al. (2002) distinguished low fluorescent granular cells and two kinds of strong fluorescent plasmatocytes: plasmatocytes 1 stained all over their surface and plasmatocytes 2 with a rather dotted appearance. Prohaemocytes were not stained at all. Marringa et al. (2014) found permeabilized cells, plasmatocytes and acellular particles. Similarly to Negri et al. (2014a). Marringa et al. (2014) postulated that bee hemocytes seemed to display a molecular ligature for binding to other cells or surfaces, and through this mechanism, a functional role in response to pathogens or wound healing. These authors also observed that the smears of bee hemolymph sometimes showed hemocyte aggregation, involving abundant numbers of permeabilized cells as well as some plasmatocytes. Interestingly, as it was pointed out by Negri et al. (2014a). Marringa et al. (2014) also related this cellular aggregation to an encapsulation process basing their suggestion on Pseudoplusia includens description by Pech and Strand 1995, 1996 and 2000; Lavine and Strand 2001.

\section{THE IMPORTANCE OF WORKING W I T H A. MELLIFERA HEMOCYTES: HONEY BEES' CELLULAR RESPONSES TO DIFFERENT THREATS}

The importance of working with $A$. mellifera hemocytes could be exemplified with recently published results demonstrating the relevance of cellular immunity in the bees' response to confront important threats such as $V$. destructor parasitism, nutrition deficiencies through habitat fragmentation, pesticide poisoning and the negative effects of winter season in temperate climates and viruses (Alaux et al. 2010a; Martin et al. 2012; Cousin et al. 2013; Steinmann et al. 2015). This section integrates the results obtained by different authors within the biological context in order to understand the significance of the data discussed (Figure 1). We suggest that the relevant results provided below support the development of new strategies to help beekeepers to control field stress.

Without treatment, a colony of A. mellifera infested with $V$. destructor dies within 1 to 3 years (Rosenkranz et al. 2010; Dietemann et al. 2012). A satisfactory solution to its control has not been described as of yet, and it has become clear that the development of enduring sustainable control measures will not occur unless a better understanding of the fundamental biology of the parasite is reached (Rosenkranz et al. 2010; Dietemann et al. 2012). The fact that a special chapter was devoted to $V$. destructor in the 'COLOSS BEEBOOK' evidences the relevance of developing a standardized methodology to fully comprehend this parasite affecting honey bees (Dietemann et al. 2013a). Alternative methods are in line with the principles of integrated pest management and have been extensively applied worldwide to enhance the chances for colony survival and ensure residue-free hive products (Rosenkranz et al. 2010; Dietemann et al. 2012). The most promising options are based on biological control using pheromones, hormones, pathogens, predators or antagonists (Rosenkranz et al. 2010; Dietemann et al. 2012).

Marringa et al. (2014) have recently provided some results that indicate that Varroa mite burden may influence hemocyte profiles in honey bees, thus evidencing that honey bees' cellular immune system responds to mite's parasitism (Figure 1).

Varroa mites (Varroa spp.) feed on the hemolymph of developing and adult bees (Rosenkranz et al. 2010). The mother mite creates a hole in the cuticle of the pupa and secretes anticoagulant factors to diminish the wound healing response of the host so that the mite nymphs can feed through the open wound. This single 'feeding zone' created by the mother mite is part of 'parental care' and it is of vital importance to reproduction success, since the soft chelicerae of the nymphal stages cannot perforate the pupal cuticle and the male's chelicerae are modified for sperm transfer (Rosenkranz et al. 2010; Richards et al. 2011). All this clearly reflects the importance of wounding in $V$. destructor reproduction.

The statements above come to show that the study of $A$. mellifera hemocytes is crucial, since 


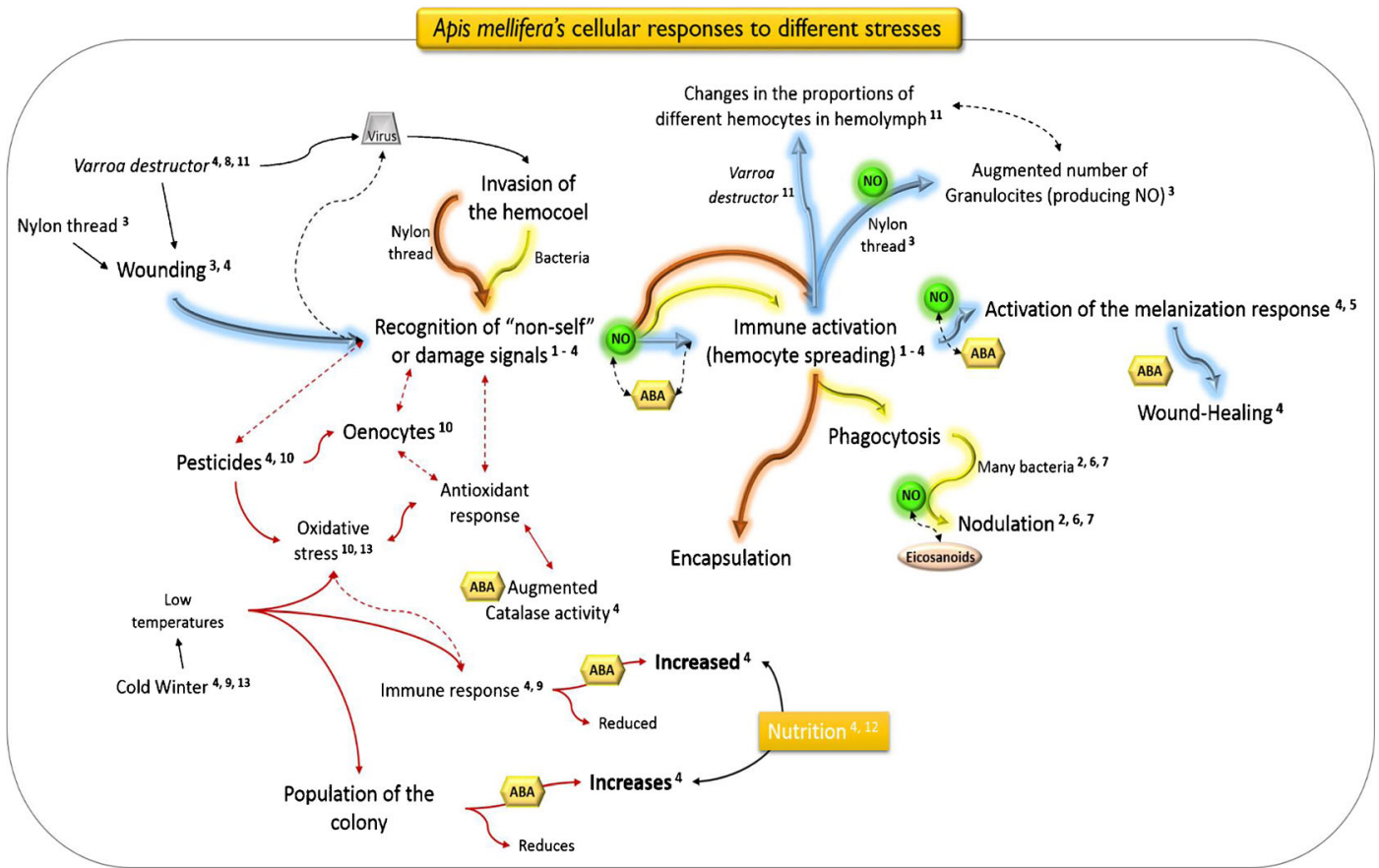

Figure 1. Schematic summary of the cellular immune responses reported in Apis mellifera triggered upon different kind of stresses. $N O$ nitric oxide. $A B A$ abscisic acid. The related stresses and cellular responses are connected through arrows of the same colour. Full arrows refer to stresses or cellular responses considered to be strongly supported by literature. Dotted arrows refer to possible or indirect relationships between stresses and/or cellular responses. The numbers indicate references supporting each stress and/or cellular responses in A. mellifera illustrated here. 1 Negri et al. 2014a. 2 Negri et al. 2013. 3 Negri et al. 2014b. 4 Negri et al. 2015. 5 Negri et al. 2012. 6 Bedick et al. 2001. 7 Gätschenberger et al. 2013. 8 Martin et al. 2012. 9 Steinmann et al. 2015. 10 Cousin et al. 2013. 11 Marringa et al. 2014. 12 Alaux et al. 2010a. 13 Aurori et al. 2014.

these cells (accompanied for the activation of the melanisation process) are the main actors in the wound healing and encapsulation responses of $A$. mellifera (Figure 1).

Through a series of correlative reports, Negri et al. (2012, 2013 and 2014b) demonstrated that nitric oxide (NO) plays a role in signalling during the wound healing and encapsulation responses, including the activation of melanin formation and the recognition of a foreign surface. Interestingly, the same authors reported that abscisic acid (ABA), a naturally occurring compound in honey bees (Lipp 1990; Negri et al. 2015) that induces NO production in animal cells (Bruzzone et al. 2007; Tossi et al. 2012). also participates in the cellular responses of $A$. mellifera and enhances the wound healing response in larvae after being parasitized with $V$. destructor (Negri et al. 2015)
(Figure 1). This means that ABA helped bees to revert the anticoagulant effects reported for the mite's saliva (Richards et al. 2011).

The alteration of bee foraging areas due to the current intensification of agriculture and landscape changes could provide deficient nutrition and, therefore, affect honey bee populations (Di Pasquale et al. 2013). The importance of nutrition on honey bees' health has been clearly demonstrated and become a topic of concern (Alaux et al. 2010a, 2011). This is further supported by beekeepers who are ranking poor nutrition and starvation as two of the main reasons for colony loss (Di Pasquale et al. 2013). Therefore, studying the relationship between nutrient availability and bee health could help to better understand the current bee losses observed at a global level (Alaux et al. 2010a; Di Pasquale et al. 2013). The studies on 
the cellular response of $A$. mellifera by Negri et al. (2015) also demonstrated that ABA could work as a new natural supplement to be used by beekeepers to confront $A$. mellifera's stresses. The relevance of the results relies on the strategy used by these authors to treat bees with ABA, supplementing bee hives with ABA-containing syrup (sucrose syrup) in the field. This enhanced the bees' immune system which was reflected at an individual and colony level, adding further evidence on the importance of nutrition in the bees' immune fitness (Negri et al. 2015).

Another important stress factor honey bees confront is intoxication with pesticides (Alaux et al. 2010b; Gregorc and Ellis 2011; Boncristiani et al. 2012; Cousin et al. 2013). These chemical compounds have extremely deleterious effects on bees' physiology (Gregorc and Ellis 2011). The cellular immune responses are believed to play an important part in defending insects from pesticide poisoning (James and Xub 2012; Cousin et al. 2013). Recently, Cousin et al. (2013) reported that exposure to very low concentrations of Paraquat induced size changes in honey bee larvae oenocytes. These authors published results demonstrating that the effects of Paraquat could be the cause of the characteristic oxidative stress produced by this pesticide. Interestingly, it has been reported that ABA, a molecule that enhances cellular responses of $A$. mellifera, also helps adult bees to tolerate higher doses of two different organic pesticides that produce oxidative stress in insect's physiology (Negri et al. 2015). The authors demonstrated that the supplementation of bees' diet with ABA increased the catalase activity of newly emerged worker bees. Thus, the augmented tolerance to pesticides observed correlates with an enhanced antioxidant and cellular aptitude (Negri et al. 2015). In 2013, Mao et al. provided evidence that $p$-coumaric acid induced the expression of detoxification genes in $A$. mellifera, enhancing bee tolerance to pesticides (Mao et al. 2013). Like ABA, $p$-coumaric acid is a natural compound present in pollen and honey. Indeed, its effects on the bees' cellular immune responses are also worth analysing.

Most of the recent major losses of managed honey bee colonies have occurred during winter, thereby suggesting that winter bees may have a compromised immune function and higher susceptibility to diseases (Gätschenberger et al. 2013; Steinmann et al. 2015). However, most studies on honey bee immunity have placed their emphasis on summer bees, while the immunity of winter bees remains to be properly explained (Steinmann et al. 2015).

The number of winter worker bees is key when it comes to evaluating colony fitness because they develop several important activities during the winter season such as thermoregulation, queen attendance, brood rearing and sporadic cleansing flights outside the hive (Gätschenberger et al. 2013). It is reasonable to assume that winter bees are well prepared to combat any microbial attack they may encounter. Winter bees do not hibernate but rather remain in a cluster inside the hive mainly engaged in thermoregulation producing heat by shivering with their flight muscles (Stabentheiner et al. 2003). This heat production is a highly energy-consuming process and relies mostly on honey reserves in a bee colony (Tautz 2008).

Recently, interesting results reported by Steinmann et al. (2015) have reflected that high loads of deforming wing virus (DWV) in winter are associated with a reduced expression of the genes involved in the cellular immune response and physiological activity. These findings are consistent with the hypothesis that sustains that the downregulation of the energetically costly immune system and physiological activity under adverse winter conditions may be a strategy to save energy and increase overwintering survival even at the expense of increased risk of virus infection. The authors hypothesized that a physiological adaptation of winter bees to increase winter survival is related to an overall decrease in physiological activity, including downregulation of the energetically expensive immune system, which results in increased susceptibility to pathogens (Steinmann et al. 2015).

In addition, winter bees have high titters of vitellogenin which is produced and secreted by the fat body, and is thought to protect bees from oxidative cellular damage in addition to other multiple functions (Seehuus et al. 2006). Furthermore, winter bees have an enlarged fat body with a high content of lipids, glycogen and 
proteins and feature a large number of hemocytes (Fluri et al. 1977).

Considering the need for an efficient cellular and humoral immune response in the winter bees detailed above, the results obtained from ABAsupplemented hives by Negri et al. (2015) represent data of high relevance. Interestingly, these authors reported that ABA enhanced hemocytic responses and the antioxidant aptitude of worker bees and that the beneficial effects of this molecule were also evidenced at a colony level: ABAsupplemented hives ended the winter season with full adult populations (worker winter bees) while the control ones reduced the number of bees to less than half (Negri et al. 2015).

\section{CONCLUDING REMARKS AND PERSPECTIVES}

This manuscript provides an in-depth summary of the literature on honey bee immunity and resistance to disease (Figure 1). As far as honey bees' defensive mechanisms are concerned, the understanding of cellular immunity could provide new views on their responses to the biotic and abiotic challenges that threaten their survival. This review evidences that cellular immunity studies contribute with useful information to design new strategies to be applied by beekeepers worldwide to confront the different stresses affecting $A$. mellifera .

We would like to underline once again the need to carry out further studies on cellular responses against bacteria and virus. There is still scarce information on specific cellular reactions to bacteria and viruses (Azzami et al. 2012; Steinmann et al. 2015). Researchers should go deeper into the study of the cellular responses used by honey bees to confront these pathogens.

A new methodical development to address the factors underlying globally observed bee losses is in urgent need. Advances in this subject are necessary for the development of field, semi-field and laboratory standard testing methods (Hendriksma et al. 2011; Dietemann et al. 2012; Alaux et al. 2014). In this sense, hard work is being directed towards the standardization of laboratory protocols in order to diminish the undesirable variability in the results worldwide (Hendriksma et al. 2011; Boughton et al.
2011). Recently, a compilation of suitable methodologies standardized to study many aspects related to honey bees in the field and in the laboratory has been published under the name of 'The COLOSS BEEBOOK' (Dietemann et al. 2013b, c). However, a compilation of the current assays and techniques available to measure cellular immune defence in $A$. mellifera was not included, perhaps due to the scant information available on this subject matter. In this regard, we believe that research groups around the globe should join their efforts and interact to develop and standardize more methodologies suitable for the study of $A$. mellifera cellular defences.

The way in which insects recognize abiotic targets remains a topic of pressing concern (Davies and Preston 1985; Mandato et al. 1996; Tojo et al. 2000). Molecules like calcium or eicosanoids have been reported to participate in hemocyte spreading after non-self recognition (Mandato et al. 1996; Tojo et al. 2000). Recently, it has been documented that $\mathrm{NO}$ acts as a signalling molecule during the first steps of hemocyte activation after non-self recognition and in the wound healing/encapsulation response (Negri et al. 2013 and 2014b). Owing to its nature, NO could either act as a second messenger within each hemocyte or as a signal between contiguous cells (Nappi and Christensen 2005; Davies and Dow 2009; Hillyer and Estévez-Lao 2010). Thus, the free radical NO should be considered as a key molecule (Rivero 2006) involved in the immune activation of $A$. mellifera hemocytes, and the connections between NO and other signal molecules like ABA, calcium or eicosanoids could be the platform for future research work on insect immunology.

\section{ACKNOWLEDGMENTS}

The authors would like to thank to the "Consejo Nacional de Investigaciones Científicas y Técnicas' (CONICET), the 'Universidad Nacional de Mar del Plata' (UNMdP) and the 'Agencia Nacional de Promoción Científica y Técnológica' (ANPCyT) for their financial support. PN is a doctoral fellow from CONICET, Argentina.

Immunité cellulaire chez Apis mellifera: l'étude des hémocytes apporte quelque lumière sur la capacité des abeilles à faire face aux menaces 


\section{Apidae/ système immunitaire/ défense cellulaire}

\section{Zelluläre Immunität bei Apis mellifera: Die Untersuchung von Hämozyten wirft Licht auf die Fähigkeit von Bienen auf Bedrohungen zu reagieren}

\section{Apis mellifera / Honigbiene / Hämozyten / Immunsystem}

\section{REFERENCES}

Alaux, C., Ducloz, F., Crauser, D., Le Conte, Y. (2010a) Diet effects on honey bee immunocompetence. Biol. Lett. 6, 562-565

Alaux, C., Brunet, J.-L., Dussaubat, C., Mondet, F., Tchamitchan, S., Cousin, M., Brillard, J., Baldy, A., Belzunces, L.P., Le Conte, Y. (2010b) Interactions between Nosema microspores and a neonicotinoid weaken honey bees (Apis mellifera). Environ. Microbiol. 12, 774-782

Alaux, C., Dantec, C., Parrinelllo, H., Le Conte, Y. (2011) Nutrigenomics in honey bees: Digital gene expression analysis of pollen's nutritive effects on healthy and varroa-parasitized bees. BMC Genomics 12, 496. doi:10.1186/1471-2164-12-496

Alaux, C., Kemper, N., Kretzschmar, A., Le Conte, Y. (2012) Brain, physiological and behavioural modulation induced by immune stimulation in honey bees (Apis mellifera): A potential mediator of social immunity? Brain. Behav. Immun. 26, 1057-1060

Alaux, C., Crauser, D., Pioz, M., Saulnier, C., Le Conte, Y. (2014) Parasitic and immune-modulation of flight activity in honey bees tracked with optical counters. J. Exp. Biol. 217, 3416-3424

Aurori, C.M., Buttstedt, A., Dezmirean, D.S., Mărghitaș, L.A., Moritz, R.F.A., Erler, S. (2014) What is the main driver of ageing in long-lived winter honeybees: antioxidant enzymes, innate immunity, or vitellogenin? J. Gerontol. A. Biol. Sci. Med. Sci. 69, 633-639

Azzami, K., Ritter, W., Tautz, J., Beier, H. (2012) Infection of honey bees with acute bee paralysis virus does not trigger humoral or cellular immune responses. Arch. Virol. 157, 689-702

Bedick, J.C., Tunaz, H., Aliza, A.R.N., Putnam, S.M., Ellis, M.D., Stanley, D.W. (2001) Eicosanoids act in nodulation reactions to bacterial infections in newly emerged adult honey bees, Apis mellifera, but not in older foragers. Comp. Biochem. Physiol. 130, 107117

Beisser, K., Munz, E., Reimann, M., Renner-Muller, I.C.E. (1990) Experimentelle Untersuchungen zur in uitroKultivierung von Zellen der Karntner Honigbiene (Apis mellifera carnica Pollmann, 1879). J. Vet. Med. 37, 509-519

Boncristiani, H., Underwood, R., Schwars, R., Evans, J.D., Pettis, J. (2012) Direct effect of acaricides on pathogen loads and gene expression levels in honey bees Apis mellifera. J. Insect Physiol. 58(5), 613-620

Boughton, R.K., Joop, G., Armitage, S.A.O. (2011) Outdoor immunology: methodological considerations for ecologists. Funct. Ecol. 25, 81-100

Bruzzone, S., Moreschi, I., Usai, C., Guida, L., Damonte, G., et al. (2007) Abscisic acid is an endogenous cytokine in human granulocytes with cyclic ADP-ribose as second messenger. Proc. Natl. Acad. Sci. 104, 5759

Clark, K.D., Pech, L.L., Strand, M.R. (1997) Isolation and identification of a plasmatocyte-spreading peptide from the hemolymph of the lepidopteran insect Pseudoplusia includens. J. Biol. Chem. 272, 2344023447

Cousin, M., Silva-Zacarin, E., Kretzschmar, A., El Maataoui, M., Brunet, J.-L., et al. (2013) Size changes in honey bee larvae oenocytes induced by exposure to paraquat at very low concentrations. PLoS ONE 8(5), e65693. doi:10.1371/journal.pone.0065693

Davies, S., Dow, J. (2009) Modulation of epithelial innate immunity by autocrine production of nitric oxide. Gen. Comp. Endocrinol. 162, 113-121

Davies, D.H., Preston, T.M. (1985) The behaviour of insect plasmatocytes in vitro: changes in morphology during settling, spreading, and locomotion. J. Exp. Zool. 236, 71

De Graaf, D.C., Dauwe, R., Walravens, K., Jacobs, F.J. (2002) Flow cytometric analysis of lectin-stained haemocytes of the honey bee (Apis mellifera). Apidologie 33, 571-579

Dean, P., Richards, E.H., Edwards, J.P., Reynolds, S.E., Charnley, K. (2004) Microbial infection causes the appearance of hemocytes with extreme spreading ability in monolayers of the tobacco hornworm Manduca sexta. Dev. Comp. Immunol. 28, 689-700

Di Pasquale, G., Salignon, M., Le Conte, Y., Belzunces, L.P., Decourtye, A., et al. (2013) Influence of pollen nutrition on honey bee health: do pollen quality and diversity matter? PLoS ONE 8(8), e72016. doi:10.1371/journal.pone.0072016

Dietemann, V., Pflugfelder, J., Anderson, D., Charrière, J.D., Chejanovsky, N., et al. (2012) Varroa destructor: research avenues towards sustainable control. J. Apic. Res. 51, 125

Dietemann, V., Nazzi, F., Martin, S.J., Anderson, D.L., Locke, B., et al. (2013a) Standard methods for varroa research. J. Apic. Res. . doi:10.3896/IBRA.1.52.1.09

Dietemann, V., Ellis, J. D., Neumann, P. (Eds) (2013b) The COLOSS BEEBOOK, Volume I: standard methods for Apis mellifera research. International Bee Research Association; Cardiff, UK. 636 pp. ISBN 978-086098-274-6

Dietemann, V., Ellis, J. D., Neumann, P. (Eds) (2013c) The COLOSS BEEBOOK, Volume II: standard methods for Apis mellifera pest and pathogen research. International Bee Research Association; Cardiff, UK. 356 pp. ISBN 978-0-86098-275-3

Eleftherianos, I., Revenis, C. (2011) Role and importance of phenoloxidase in insect hemostasis. J. Innate Immun. 3, 28-33 
Eleftherianos, I., Xu, M., Yadi, H., French-Constant, R.H., Reynolds, S.E. (2009) Plasmatocyte-spreading peptide (PSP) plays a central role in insect cellular immune defences against bacterial infection. J. Exp. Biol. 212, 1840-1848

Evans, J.D., Aronstein, K., Chen, Y.P., Hetru, C., Imler, J.L., Jiang, H., Kanost, M., Thompson, G.J., Zou, Z., Hultmark, D. (2006) Immune pathways and defence mechanisms in honey bees Apis mellifera. Insect Mol. Biol. 15, 645-656

Fluri, P., Wille, H., Gerig, L., Luscher, M. (1977) Juvenile hormone, vitellogenin and hemocyte composition in winter honey bees (Apis mellifera). Cell. Mol. Life Sci. 33, 1240-1241

Gätschenberger, H., Azzami, K., Tautz, J., Beier, H. (2013) Antibacterial immune competence of honey bees (Apis mellifera $)$ is adapted to different life stages and environmental risks. PLoS ONE 8 (6), e66415. doi:10.1371/journal.pone.0066415

Gillespie, J.P., Kanost, M.R. (1997) Biological mediators of insect immunity. Annu. Rev. Entomol. 42, 611-43

Gregorc, A., Ellis, J.D. (2011) Cell death localization in situ in laboratory reared honey bee larvae treated with pesticides (Apis mellifera L.). Pesticide Biochem. Physiol. 99, 200-207

Hendriksma, H.P., Hartel, S., Steffan-Dewenter, I. (2011) Honey bee risk assessment: new approaches for in vitro larvae rearing and data analyses. Met. Ecol. Evol. . doi:10.1111/j.2041-210X.2011.00099.x

Hillyer, J., Estévez-Lao, T. (2010) Nitric oxide is an essential component of the hemocyte-mediated mosquito immune response against bacteria. Dev. Comp. Immunol. 34, 141-149

Horohov, D.W., Dunn, P.E. (1983) Phagocytosis and nodule formation by hemocytes of Manduca sexta following injection of Pseudomonas aeruginosa. J. Invertebr. Pathol. 41, 203-213

James, R.R., Xub, J. (2012) Mechanisms by which pesticides affect insect immunity. J. Invertebr. Pathol. 109, 175

Jefferson, J., Dolstad, H., Sivalingam, M., Snow, J. (2013) Barrier immune effectors are maintained during transition from nurse to forager in the honey bee. PLoS ONE 8(1), e54097. doi:10.1371/journal.pone.0054097

Laughton, A.M., Boots, M., Siva-Jothy, M.T. (2011) The ontogeny of immunity in the honey bee. Apis mellifera L. following an immune challenge. J. Insect Physiol. 57, 1023-1032

Lavine, M.D., Strand, M.R. (2001) Surface characteristics of foreign targets that elicit an encapsulation response by the moth Pseudoplusia includens. J. Insect Physiol. 47, 965-974

Lipp, J. (1990) Nachweis und herkunft von abscisinsäure und prolin in honig. Apidologie 21, 249

Mandato, C.A., Diehl-Jones, W., Moore, S.J., Downer, R.G.H. (1996) The effects of eicosanoid biosynthesis inhibitors on prophenoloxidase activation, phagocytosis and cell spreading in Galleria mellonella. J. Insect Physiol. 43, 1-8
Manfredini, F., Dallai, R., Ottaviani, E. (2008) Circulating hemocytes from larvae of the paper wasp Polistes dominulus (Hymenoptera, Vespidae). Tissue and Cell 40, 103-112

Mao, W., Schuler, M. A., Berenbaum, M. R. (2013) Honey constituents up-regulate detoxification and immunity genes in the western honey bee Apis mellifera. Proc. Natl. Acad. Sci., doi:10.1073/pnas.1303884110

Markus, R., Kurucz, E., Rus, F., Andó, I. (2005) Sterile wounding is a minimal and sufficient trigger for a cellular immune response in Drosophila melanogaster. Immunol. Lett. 101, 108-111

Marmaras, V.J., Lampropoulou, M. (2009) Regulators and signalling in insect haemocyte immunity. Cell. Signal. 21, 186-195

Marringa, W.J., Krueger, M.J., Burritt, N.L., Burritt, J.B. (2014) Honey bee hemocyte profiling by flow cytometry. PLoS ONE 9 (10), e108486. doi:10.1371/ journal.pone. 0108486

Martin, S.J., Highfield, A.C., Brettell, L., Villalobos, E.M., Budge, G.E., Powell, M., Nikaido, S., Schroeder, D.C. (2012) Global honey bee viral landscape altered by a parasitic mite. Science 336, 1304

Nappi, A., Christensen, B. (2005) Melanogenesis and associated cytotoxic reactions: Applications to insect innate immunity. Insect Biochem. Mol. Biol. 35, 443-459

Nardi, J.B., Pilas, B., Bee, M.C., Zhuang, S., Garsha, K., Kanost, M.R. (2006) Neuroglian-positive plasmatocytes of Manduca sexta and the initiation of hemocyte attachment to foreign surfaces. Dev. Comp. Immunol. 30 , 447-462

Negri, P., Maggi, M.D., Massazza, D., Correa-Aragunde, N., Eguaras, M.J., Lamattina, L. (2012) Nitric Oxide stimulates melanin production during immune response in Apis mellifera. Biocell 36, 68

Negri, P., Maggi, M., Correa-Aragunde, N., Brasesco, C., Eguaras, M., Lamattina, L. (2013) Nitric oxide participates at the first steps of Apis mellifera cellular immune activation in response to non-self recognition. Apidologie 44, 575-585

Negri, P., Maggi, M., Szawarski, N., Lamattina, L., Eguaras, M. (2014a) Apis mellifera hemocytes invitro: What type of cells are they? Functional analysis before and after the pupae metamorphosis black box. J. Apic. Res. 53 , 576-589. doi:10.3896/IBRA.1.53.5.11

Negri, P., Quintana, S., Maggi, M., Szawarski, N., Lamattina, L., Eguaras, M. (2014b) Apis mellifera hemocytes generate increased amounts of nitric oxide in response to wounding/encapsulation. Apidologie 45, 610-617

Negri, P., Maggi, M., Ramirez, L., De Feudis, L., Szawarski, N., Quintana, S., Eguaras, M., Lamattina, L. (2015) Abscisic acid enhances the immune response in Apis mellifera and contributes to the colony fitness. Apidologie . doi:10.1007/s13592-014-0345-7

Neumann, P., Yañez, O., Fries, I., de Miranda, J.R. (2012) Varroa invasion and virus adaptation. Trends Parasitol. . doi:10.1016/j.pt.2012.06.004 
Pech, L.L., Strand, M.R. (1995) Encapsulation of foreign targets by hemocytes of the moth Pseudoplusia includens (Lepidoptera: Noctuidae) involves an RGD-dependent cell adhesion mechanism. J. Insect Physiol. 41, 481-488

Pech, L., Strand, M. (1996) Granular cells are required for encapsulation of foreign targets by insect haemocytes. J. Cell Sci. 109, 2053-2060

Pech, L.L., Strand, M.R. (2000) Plasmatocytes from the moth Pseudoplusia includens induce apoptosis of granular cells. J. Insect Physiol. 46, 1565-1573

Price, C.D., Ratcliffe, A. (1974) A Reappraisal of insect haemocyte classification by the examination of blood from fifteen insect orders. Z. Zellforsch 147, 537-549

Richards, E., Jones, B., Bowman, A. (2011) Salivary secretions from the honey bee mite, Varroa destructor: effects on insect hemocytes and preliminary biochemical characterization. Parasitology 138, 602-608

Rivero, A. (2006) Nitric oxide: an antiparasitic molecule of invertebrates. Trends Parasitol. 22, 219-225

Rosenkranz, P., Aumeier, P., Ziegelmann, B. (2010) Biology and control of Varroa destructor. J. Invertebr. Pathol. 103, 96-119

Sapcaliu, A., Radoi, I., Pavel, C., Tudro, N., Cauia, E., Siceanu, A., Meiu, F. (2009) Research regarding haemocyte profile from Apis mellifera carpatica bee hemolymph originated in the south of Romania. Lucrări stiintifice medicină veterinară XLII

Schmid, M.R., Brockmanna, A., Pirka, C.W.W., Stanley, D.W., Tautz, J. (2008) Adult honey bees (Apis mellifera $L$.) abandon hemocytic, but not phenoloxidase-based immunity. J. Insect Physiol 54, 439-444

Schmid-Hempel, P. (2005) Evolutionary ecology of insect immune defences. Annu. Rev. Entomol. 50, 529-551

Seehuus, S.C., Norberg, K., Gimsa, U., Krekling, T., Amdam, G.V. (2006) Reproductive protein protects functionally sterile honey bee workers from oxidative stress. Proc. Natl. Acad. Sci. 103, 962-967
Stabentheiner, A., Pressl, H., Papst, T., Hrassnigg, N., Crailsheim, K. (2003) Endothermic heat production in honey bee winter clusters. J. Exp. Biol. 206, 353358

Steinmann, N., Corona, M., Neumann, P., Dainat, B. (2015) Overwintering is associated with reduced expression of immune genes and higher susceptibility to virus infection in honey bees. PLoS ONE 10 (6), e0129956. doi:10.1371/journal.pone.0129956

Strand, M.R. (2008) The insect cellular immune response. Insect Sci. 15, 1-14

Tautz, J. (2008) The buzz about bees. Springer, Berlin Heidelberg. $284 \mathrm{p}$

Tojo, S., Naganuma, F., Arakawa, K., Yokoo, S. (2000) Involvement of both granular cells and plasmatocytes in phagocytic reactions in the greater wax moth. Galleria mellonella. J. Insect Physiol. 46, 1129-1135

Tossi, V., Cassia, R., Bruzzone, S., Zochi, E., Lamattina, L. (2012) ABA says NO to UV-B: A universal response? Trends Plant Sci. 17, 510-517

Van Steenkiste, D., Raes, H., Jacobs, F. (1988) Hemocytes of adult honey bees (Apis mellifera). Ann. Soc. R. Zool. Belgique 118, 234-235

Wagoner, K., Boncristiani, H., Rueppell, O. (2013) Multifaceted responses to two major parasites in the honey bee (Apis mellifera). BMC Ecology 13, 26

Wienand, A., Madel, G. (1988) Haemocytes of the honey bee, Apis mellifera, and their changes by varroatosis (Hymenoptera: Apidae). Entomol. Gen. 14, 81-92

Wilson-Rich, N., Dres, D., Starks, P. (2008) The ontogeny of immunity: Development of innate immune strength in the honey bee (Apis mellifera ). J. Insect Physiol. 54, 1392-1399

Wilson-Rich, N., Spivak, M., Fefferman, N.H., Stark, P.T. (2009) Genetic, individual, and group facilitation of disease resistance in insect societies. Annu. Rev. Entomol. 54, 405-23 